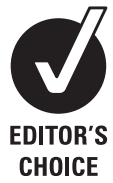

Danish Center for Sleep Medicine, Department of Clinical Neurophysiology, Center for Healthy Ageing, Faculty of Health Sciences, University of Copenhagen, Glostrup Hospital Copenhagen, Denmark ${ }^{2}$ Danish Institute for Health Services Research, Copenhagen, Denmark

\section{Correspondence to} Professor Poul Jennum, Danish Center for Sleep Medicine, Department of Clinical Neurophysiology, Faculty of Health Sciences, University of Copenhagen, Glostrup Hospital DK 2600 Glostrup, Denmark; poje@glo.regionh.dk

Received 30 May 2010 Accepted 11 November 2010 Published Online First 2 January 2011

\title{
Health, social and economical consequences of sleep-disordered breathing: a controlled national study
}

\author{
Poul Jennum, ${ }^{1}$ Jakob Kjellberg ${ }^{2}$
}

\begin{abstract}
Background The objective direct and indirect costs of sleep-disordered breathing (snoring, sleep apnoea (SA) and obesity hypoventilation syndrome (OHS)) and the treatment are incompletely described.

Methods Using data from the Danish National Patient Registry (1998-2006), 12 045, 19438 and 755 patients were identified with a diagnosis of snoring, SA and OHS respectively. For every patient, four age-, sex- and socioeconomic-matched citizens were randomly selected (48 180, 77752 and 3020, respectively) from the Danish Civil Registration System Statistics Direct costs were extracted from the Danish Ministry of Health, Danish Medicines Agency and National Health Security and indirect costs were based on data derived from the Coherent Social Statistics.
\end{abstract}

Results Snoring, and especially SA and OHS, were associated with significantly higher rates of health-related contact, medication use, unemployment and accounted for increased socioeconomic costs (especially indirect costs). These effects increased with the severity of SA and patients with OHS had the lowest employment rates. The income level of patients with SA and OHS who were employed was lower than that of employed control subjects. The annual excess total direct and indirect costs for patients with snoring, SA and OHS were $€ 705$, $€ 3860$ and $€ 11320$, respectively. Patients with snoring, $S A$ and OHS received an annual mean excess social transfer income of $€ 147$, $€ 879$ and $€ 3263$, respectively. These socioeconomic consequences were present up to 8 years prior to the first diagnosis in patients with $\mathrm{SA}$ and $\mathrm{OHS}$, and further increased with disease advancement. Treatment with continuous positive airway pressure (CPAP) reduced mortality in patients with SA but not in those with $\mathrm{OHS}$ within an observation period of 2 years. Conclusion Sleep-disordered breathing has major socioeconomic consequences for the individual patient and for society. Although CPAP treatment reduces mortality, earlier disease detection could have a greater impact on disease complications.

\section{INTRODUCTION}

Snoring, sleep apnoea (SA) and obesity hypoventilation syndrome (OHS) - described jointly as sleep-disordered breathing (SDB)-are common disorders that affect a significant proportion of the population. ${ }^{1}$ These disorders increase the risk of cardiovascular and cerebrovascular (CVD) morbidity and mortality Additional effects of SDB include reduced social function and quality of life. Because these disorders are chronic, they may also have a deleterious effect on a patient's employment status and ability to work.
Significant progress has been made in understanding the best methods of diagnosing and managing SDB, including simpler diagnostic procedures and treatment with continuous positive airway pressure (CPAP) which reduces the associated CVD morbidity and mortality and improves social functioning and other consequences of SDB. ${ }^{23}$ Despite this progress, SDB remains undiagnosed or untreated, especially among high-risk groups such as patients with CVD morbidities. ${ }^{4-6}$

Given the evidence presented, it is clear that SDB may create a significant socioeconomic burden However, estimates of the socioeconomic impact of SDB have only been conducted using questionnaires in select patient groups or using a model-based approach. ${ }^{7-14}$ Furthermore, the information and assumption of costs have focused on direct costs because indirect costs have generally not been available or have been difficult to obtain. As such, an estimate of total disease cost-including treated and non-treated patients-has not yet been developed.

In Denmark it is possible to calculate direct and indirect costs of disease because information from all patients attending public and private hospitals and from clinics in the secondary and primary care sectors-including medication, social, income and employment data-is registered in a central database (National Patient Registry (NPR)). Using the NPR, we conducted a study to evaluate the socioeconomic consequences of SDB (with and without treatment) in Denmark. The purpose of this paper is to focus on the total health cost per case among identified patients, independent of treatment level.

\section{METHODS}

\section{Literature search}

We have reviewed the literature using the MeSH term 'cost' and 'sleep disordered breathing (snoring, sleep apnoea and OHS)' using the Pubmed database.

\section{Cost estimates}

Cost-of-illness studies measure the economic burden resulting from disease and illness across a defined population, including both direct and indirect costs. In our study, direct illness costs included the costs of hospitalisation and outpatient visits weighted by use according to diagnosisrelated groups (DRG), and specific outpatient direct illness costs were based on data from the Danish Ministry of Health. The use and costs of drugs were based on data from the National Danish Medicine Agency which includes the retail price of the drug (including dispensing costs) multiplied by the number of transactions. The frequencies and costs 
of consultations with general practitioners and other specialists were based on data from the National Health Security. Indirect costs estimate the production loss related to disease-related work disability measures by loss of income using the human capital approach. ${ }^{15}$ It is important to distinguish costs from monetary transfer payments such as disability and welfare payments. Such payments represent a transfer of purchasing power to the recipients from the general taxpayer but do not represent a net increase in the use of resources and are therefore not included in the total cost estimate. Indirect costs were based on income data from the Coherent Social Statistics.

We estimated the economic consequence of SDB by determining the annual cost of illness per patient diagnosed with snoring (ICD DG065), SA (ICD DG473) and OHS (ICD DG662) and compared the calculation with the cost in a matched control group. The health cost was divided into annual direct and indirect healthcare costs. Costs were measured on a yearly basis and adjusted to 2006 prices using the health sector price index for health sector costs, and the general price index was applied to non-medical costs. All costs were measured in DKK and converted into euros $(€ 1=\mathrm{DKK} 7.45)$.

All contacts in the primary sector (general practice and specialists in the primary sector) and the use of medication are coded in the National Health Security and the Danish Medicine Agency, respectively.

\section{Subjects}

All patient contacts are recorded in the NPR by date of contact. The NPR includes administrative information, primary and secondary diagnoses and diagnostic (eg, polysomnography, limited-channel polysomnography or respiratory polygraphy (RP), oximetry) and treatment (eg, CPAP, surgery) procedures using the International Classification of Diseases (ICD-10). In Denmark almost all patients are evaluated using RP. However, specific clinical information such as result of RP, body mass index and blood pressure are not included in this analysis as these data are incomplete. The use of SDB refers to the American Academy of Sleep Medicine (AASM) recommendation, reported in a national health technology assessment. ${ }^{16}$

Using the NPR, we identified all patients who were diagnosed with SDB from 1998 to 2006. Then, using data from the Civil Registration System Statistics Denmark, we randomly selected citizens who had the same age and sex as the patients but without any of the SDB diagnoses. Parity in socioeconomic status (SES) was developed by selecting control subjects from the same part of the country in which the patient lived, using 271 geographical areas defining the municipality borders prior to 2005 with an average of 20000 persons in each geographical area.

The ratio of control subjects to patients was 4:1. Data from patients and matched control subjects that could not be identified in the Coherent Social Statistics database were excluded from the sample. More than $99 \%$ of the observations in both groups were successfully matched. Patients and matched control subjects were followed from their year of diagnosis until 2006.

\section{Statistical analysis}

Statistical analysis was performed using SAS Version 9.1.3. The results are presented as means because some patients had a very high resource consumption which, despite leading to a skewed distribution, would not be adequately represented if the data were presented as median values. Extreme values were manually validated and no errors were identified. The statistical significance of the cost estimates was generated using a non-parametric bootstrap analysis. ${ }^{17}$

\section{RESULTS}

We identified 12 045, 19438 and 755 patients, respectively, with a diagnosis of snoring, SA or OHS, and compared their data with information from 48 180, 77752 and 3020 control subjects. The age distribution of the patients and control subjects is shown in table 1. As expected, most of the patients with an initial diagnosis of SA were middle-aged, with one-quarter being women and approximately one-tenth being children or adolescents.

\section{Direct costs as outpatient clinic costs, hospital costs, primary care costs and drug costs}

More patients than control subjects were treated in outpatient clinics, were hospitalised and had contact with the primary care system. More patients than control subjects were taking medication and more patients were receiving public support for their medications (table 2), an effect that was most pronounced for patients with SA and OHS.

\section{Total direct and indirect costs, social costs, employment rate and income}

More patients than control subjects received social services. Fewer patients with SA or OHS than control subjects received income from employment (table 3 ). The employment rate (and the total corresponding direct and indirect costs per year 8 years before and after a diagnosis was established) are shown in figure 1 for all diagnoses. Overall, the employment rate decreased with increasing age in all groups and there were no differences in employment rates between snorers and control subjects either before or after a diagnosis or treatment was established. However, the employment rates for patients with SA, and especially for those with OHS, were significantly lower up to 8 years before a diagnosis was established and further decreased after a diagnosis had been made compared with control subjects. In addition, a corresponding increase in social transfer expenses was made to patients. The rate of retirement was similar in subjects with and without SDB (data not shown). The corresponding expenses in total direct and indirect costs were increased before a diagnosis of SA and OHS was made and further increased afterwards. The social implication of OHS is particularly illustrated by the lower employment rate of snorers compared with the control group (which is similar to the Danish population), and by the much lower employment rate and higher total direct and indirect costs

Table 1 Age and sex distribution of patients and associated controls

\begin{tabular}{llll}
\hline & Snorers & SA & OHS \\
\hline $\begin{array}{l}\text { Total/women (\%) } \\
\text { Age (years) }\end{array}$ & $12045 / 2833(24)$ & $19438 / 4304(22)$ & $755 / 247(33)$ \\
$<20$ & $1057(9)$ & $1931(10)$ & $5(1)$ \\
$20-29$ & $954(8)$ & $861(4)$ & $22(3)$ \\
$30-39$ & $2262(19)$ & $2417(12)$ & $76(10)$ \\
$40-49$ & $3171(26)$ & $4201(22)$ & $150(20)$ \\
$50-59$ & $3038(25)$ & $5696(29)$ & $244(32)$ \\
$60-69$ & $1254(10)$ & $3287(17)$ & $159(21)$ \\
$70-79$ & $275(2)$ & $920(5)$ & $81(11)$ \\
$\geq 80$ & $34(0)$ & $125(1)$ & $18(2)$ \\
\hline
\end{tabular}

Data are presented as $\mathrm{n}(\%)$.

The 12045 people who snored were matched with 48180 control subjects; the 19438 with sleep apnoea were matched with 77752 control subjects; the 755 with obesity hypoventilation syndrome were matched with 3020 subjects. OHS, obesity hypoventilation syndrome; SA, sleep apnoea. 
Table 2 Distribution of contacts within the primary and secondary sector, use of public health insurance and earned income (data presented as percentage of number of people receiving or providing the activity)*

\begin{tabular}{|c|c|c|c|c|c|c|}
\hline & \multicolumn{2}{|l|}{ Snorers } & \multicolumn{2}{|l|}{ SA } & \multicolumn{2}{|l|}{ OHS } \\
\hline & $\begin{array}{l}\text { Patients } \\
(\mathrm{N}=12045)\end{array}$ & $\begin{array}{l}\text { Controls } \\
(N=48180)\end{array}$ & $\begin{array}{l}\text { Patients } \\
(\mathrm{N}=19438)\end{array}$ & $\begin{array}{l}\text { Controls } \\
(\mathrm{N}=77 \text { 752) }\end{array}$ & $\begin{array}{l}\text { Patients } \\
(\mathrm{N}=755)\end{array}$ & $\begin{array}{l}\text { Controls } \\
(N=2588)\end{array}$ \\
\hline Ambulatory treatment & $56 \dagger$ & 26 & $60 \dagger$ & 25 & $63 \dagger$ & 27 \\
\hline In-hospital treatment & $26 \dagger$ & 10 & $32 \dagger$ & 10 & $53 \dagger$ & 13 \\
\hline Medication & $83 \dagger$ & 67 & $85 \dagger$ & 67 & $95 \dagger$ & 76 \\
\hline Public health insurance & $97 \dagger$ & 90 & $96 \dagger$ & 89 & $98 \dagger$ & 93 \\
\hline Total transfer income: & $42 \dagger$ & 38 & $49+$ & 41 & $78 \dagger$ & 60 \\
\hline Pension & 11 & 10 & 15 & 16 & $25 \dagger$ & 33 \\
\hline Other public transfers & 22 & 21 & 25 & 19 & $47 \dagger$ & 21 \\
\hline Sick pay (public funded) & 15 & 10 & 15 & 10 & 14 & 10 \\
\hline Labour income & 72 & 70 & 61 & 63 & $39 \dagger$ & 53 \\
\hline
\end{tabular}

in the OHS control group (selection made by social compensation). The peak in expenses at time of all diagnoses is due to direct costs related to disease management (diagnosis and treatment).

\section{Total health costs per year}

The sources of information and the average annual health cost per person year by cost categories in Denmark compared with that of age-, sex- and SES-matched control subjects are shown in table 4. Direct net health costs (GP services, hospital services and medication) and indirect costs (loss of labour market income) for patients compared with control subjects were as follows: snorers, $€ 1899$ vs $€ 1194$ ( $p<0.0001) ;$ SA, $€ 5257$ vs $€ 1396$ $(p<0.0001)$; OHS, $€ 13050$ vs $€ 1730$ ( $p<0.0001)$. These results correspond with an annual mean excess health-related cost for each patient with snoring, SA and OHS of $€ 705$, $€ 3860$ and $€ 11320$, respectively.

\section{Influence of age and sex on employment and direct and indirect costs}

For all ages the direct costs were higher in patients, especially those with SA and OHS. Patients with SA and OHS had a lower income at all ages, especially women (data not shown).

\section{Influence of CPAP and surgery on mortality, direct and indirect costs}

There was no difference in mortality among snorers and controls in a 2-year follow-up (3.4\% vs 3.9\%), whereas patients with SA and OHS had significantly higher mortality rates compared with controls (6.1\% vs $4.4 \%, p<0.0001$ and $25.4 \%$ vs $6.8 \%, p<0.001$, respectively, adjusted for age, sex and social status). In the database, 836, 4054 and 62 patients with snoring, SA and OHS, respectively, were reported to be treated with CPAP for a period of at least 2 years with annual follow-up. CPAP had no effect on 2 -year mortality in snorers (3.8\% vs $3.4 \%$ ) but reduced mortality in patients with SA ( $5.5 \%$ vs $5.5 \%, \mathrm{p}<0.01)$. However, in patients with OHS the mortality among those treated with CPAP $(\mathrm{N}=62)$ was higher than in untreated patients $(40.3 \%$ vs $24.0 \%$, $\mathrm{p}<0.0001)$. We further analysed the influence of factors that influence mortality. Age $<40$ years, female gender and CPAP treatment were significantly associated with a better prognosis for patients with SA. Surgery (uvulopalatopharyngoplasty, UPPP) had no influence on mortality among 408 snorers and 727 patients with SA. No patients with OHS were treated with UPPP.

The costs were calculated for snorers and patients with SA for a 4 -year period. The analysis was not performed for patients with OHS because of the small statistical sample. The direct and indirect costs were all higher in treated patients with snoring, SA and OHS in the 2-year follow-up period compared with 2 years before the diagnoses (table 5). Thus, we could not identify a reduction in hospital, ambulatory or drug costs by these treatments within the 2-year observation period. We therefore subdivided the costs for snoring and SA according to the treatment modalities. Differences were identified between treated and control groups. There seems to be little variation between patient groups with different treatment modalities for snorers, but CPAP treatment had a greater effect in patients

Table 3 Percentages of patients with a diagnosis of snoring, sleep apnoea, or obesity hypoventilation syndrome and control subjects who are (1) employed, on leave or students, (2) receiving public transfer income due to unemployment, social transfer payments, or (3) retired

\begin{tabular}{|c|c|c|c|c|c|c|}
\hline & \multicolumn{2}{|l|}{ Snorers } & \multicolumn{2}{|l|}{ SA } & \multicolumn{2}{|l|}{ OHS } \\
\hline & $\begin{array}{l}\text { Patients } \\
(\mathrm{N}=12 \text { 045) }\end{array}$ & $\begin{array}{l}\text { Controls } \\
(\mathrm{N}=48 \text { 180) }\end{array}$ & $\begin{array}{l}\text { Patients } \\
(\mathrm{N}=19 \text { 438) }\end{array}$ & $\begin{array}{l}\text { Controls } \\
(\mathrm{N}=77752)\end{array}$ & $\begin{array}{l}\text { Patients } \\
\text { (N=755) }\end{array}$ & $\begin{array}{l}\text { Controls } \\
\text { (N)=2588 }\end{array}$ \\
\hline Employed, on leave or students & 71 & 71 & $60^{*}$ & 64 & $37^{*}$ & 55 \\
\hline $\begin{array}{l}\text { Receiving public transfer } \\
\text { income due to unemployment, } \\
\text { social transfer payments }\end{array}$ & 14 & 14 & $18^{*}$ & 13 & $37^{*}$ & 14 \\
\hline $\begin{array}{l}\text { Receiving pension benefits } \\
\text { payable between early retirement } \\
\text { and normal retirement pension }\end{array}$ & 11 & 11 & 17 & 18 & 23 & 29 \\
\hline Other & 4 & 5 & 5 & 5 & 2 & 2 \\
\hline
\end{tabular}


Figure 1 Percentage of employed patients and controls (left) and average yearly direct medical expenses (right) with a diagnosis of snoring, obstructive sleep apnoea (OSA) and obesity hypoventilation syndrome (OHS) at time of diagnosis and 8 years before and after the diagnosis was established. Note that the scales for the diseases are different: the costs for the patients and control groups with $\mathrm{OHS}$ are much higher.

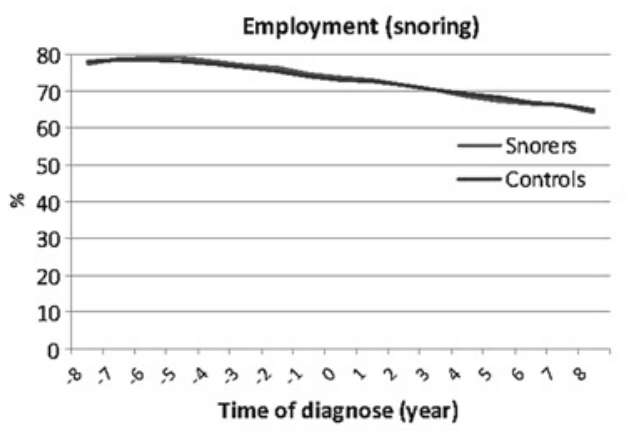

Employment (OSA)

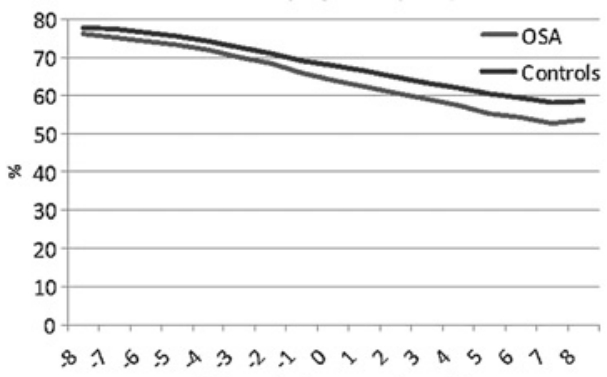

Time of diagnose (year)

Employment (OHS)

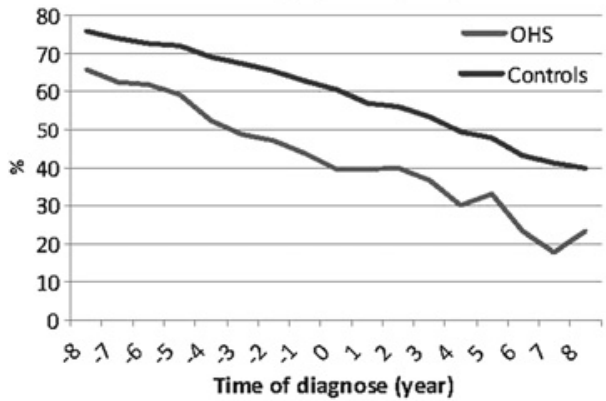

Yearly medical expenses (snoring)

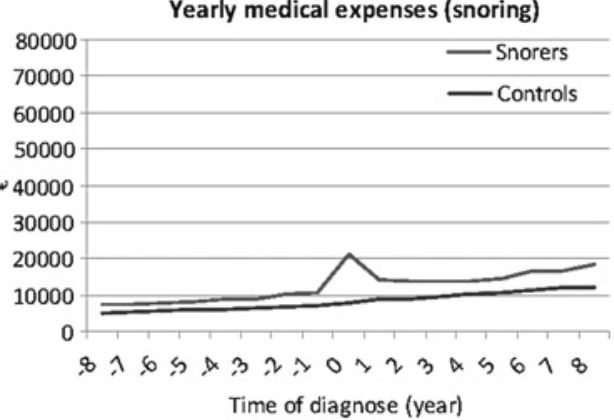

Yearly medical expenses (OSA)

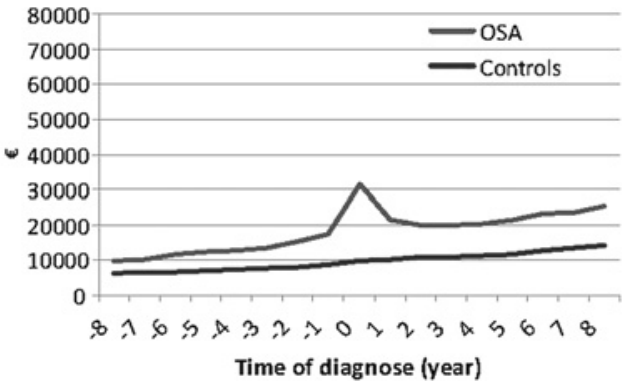

Yearly medical expenses (OHS)

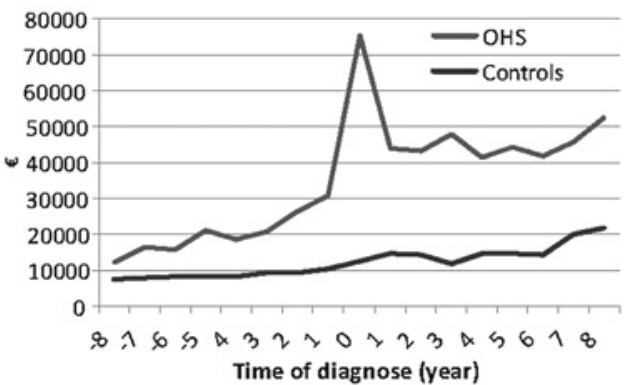

with SA (table 6). It is noteworthy that the cost decreased in year 2 in all groups, but not to the level 2 years prior to treatment initiation (data not shown).

\section{DISCUSSION}

This study, which evaluated the direct and indirect objective socioeconomic impact of SDB in a complete national sample, found that snoring in part, and especially SA and OHS, have a significant socioeconomic impact compared with a random population-based sample controlled for SES. These effects are present several years before a diagnosis is established. This contrasts with previous estimates that have applied measures on selected patient groups without controls and involved financial modelling rather than the use of more directly derived costs.

Patients with SA and OHS had medication and hospital costs 2-3 times higher than controls, total health costs that were more than twice as high and employment rates that were more than 30\% lower. Patients with OHS had the lowest employment rate. Employed patients earned only two-thirds of the income of control subjects, with patients with OHS having the lowest earnings. Patients with SA or OHS had much higher social expenditure than control subjects. Thus SA, and especially OHS, has a major impact on social outcome including employment. This is probably due to a complex interaction between comorbidity and lever of adiposity which has a major influence on SES and employment level.
These results do not reflect the individual impact of SDB alone as levels of comorbidity (eg, obesity, smoking, craniofacial abnormalities) and social factors associated with these diseases will differ between the groups. However, by adjusting for SES, we have tried to minimise the effect that these factors may have had on our results. This can best be illustrated by comparing the patients with SA and those with OHS with a random population-based sample. Without adjustment for SES, the differences in the results are even larger (eg, the employment rate in the OHS group is less than $50 \%$ that of the general population). We therefore believe that the estimates we present represent a realistic objective estimate of indirect and direct costs of SDB of various severities in a national sample of identified patients.

Determining the economic consequences of SDB is complex. With an accurate diagnosis and appropriate treatment, patients decrease their risk of CVD complications and the associated costs but the diagnostic procedures, treatment and management of SDB add to the direct costs. However, even when we included the costs associated with the diagnosis and treatment of SDB, our study showed that patients with SDB incur a significant socioeconomic burden because their lower employment rates and the lower earning potential among those who are employed exceed the direct costs of the disease. Because these factors influence cost, they should be included in the disease burden.

The impact of SDB on work capability is considerable. As can be seen from figure 1, patients already had a significantly reduced 
Table 4 Direct and indirect illness costs and cost sources of such information (all costs given in euros)*

\begin{tabular}{|c|c|c|c|c|c|c|c|}
\hline \multirow[b]{2}{*}{ Category of data } & \multirow[b]{2}{*}{ Sources } & \multicolumn{2}{|l|}{ Snorers } & \multicolumn{2}{|l|}{ SA } & \multicolumn{2}{|l|}{ OHS } \\
\hline & & $\begin{array}{l}\text { Patients } \\
(\mathrm{N}=59223) \dagger\end{array}$ & $\begin{array}{l}\text { Controls } \\
(\mathrm{N}=235507)\end{array}$ & $\begin{array}{l}\text { Patients } \\
(\mathrm{N}=\mathbf{8 1} 250)\end{array}$ & $\begin{array}{l}\text { Controls } \\
(N=325985)\end{array}$ & $\begin{array}{l}\text { Patients } \\
(\mathrm{N}=2255)\end{array}$ & $\begin{array}{l}\text { Controls } \\
(N=10708)\end{array}$ \\
\hline \multicolumn{8}{|l|}{ Direct health costs } \\
\hline Primary sector & $\begin{array}{l}\text { National Health Insurance Security } \\
\text { System }\end{array}$ & $286 \neq$ & 142 & $347 \neq$ & 203 & $393 \ddagger$ & 221 \\
\hline Inpatient cost & Danish Ministry of Heath & $990 \ddagger$ & 614 & $1714 \ddagger$ & 753 & $5036 \ddagger$ & 957 \\
\hline Outpatient cost & Danish Ministry of Heath & $284 \ddagger$ & 142 & $334 \ddagger$ & 157 & $392 \ddagger$ & 181 \\
\hline Drugs & Danish Medicines Agency & $393 \neq$ & 246 & $589 \neq$ & 283 & $1072 \ddagger$ & 372 \\
\hline Total direct health costs & & $1953 \ddagger$ & 1194 & $2983 \ddagger$ & 1396 & $6893 \ddagger$ & 1730 \\
\hline \multicolumn{8}{|l|}{ Difference } \\
\hline Labour market income & Coherent Social Statistics & 27638 & 27584 & $22061 \neq$ & 24334 & $13021 \ddagger$ & 19177 \\
\hline Indirect cost & & -54 & & 2273 & & 6157 & \\
\hline Sum of direct and indirect costs & & $1899 \neq$ & 1194 & $5257 \ddagger$ & 1396 & $13050 \ddagger$ & 1730 \\
\hline Net yearly costs & & 705 & & 3860 & & 11320 & \\
\hline Social transfer payments & Coherent Social Statistics & $4252 \ddagger$ & 4105 & $5646 \ddagger$ & 4767 & $9798 \ddagger$ & 6535 \\
\hline Pensions & & 1350 & 1338 & $1899 \ddagger$ & 2062 & $2659 \ddagger$ & 3714 \\
\hline Other public transfers & & 2342 & 2347 & $3052 \ddagger$ & 2235 & $6319 \neq$ & 2456 \\
\hline Sick pay (public funded) & & $538 \neq$ & 379 & $640 \neq$ & 365 & $814 \ddagger$ & 365 \\
\hline
\end{tabular}

*Bootstrap.

†Number of observation years.

$\neq \mathrm{p}<0.0001$.

OHS, obesity hypoventilation syndrome; SA, sleep apnoea.

employment status and a higher level of direct and indirect costs before the diagnosis was established and further reductions occurred after the diagnosis was made. This finding was most pronounced for patients with OHS. Several factors may explain this: (1) patients may have had symptoms or disease manifestations that affected their working ability long before the diagnosis was made; (2) patients may not have been able to seek a pension before they received a diagnosis so they maintained their employment before their diagnosis was established; (3) patients may only have sought professional help when they reached an impasse in their social lives and their symptoms led to exhaustion. These factors are most important in younger age groups in whom the impact of indirect costs such as ability to work is most pronounced. As disease management (prevention and treatment) of SDB affects direct and indirect costs, early intervention is most important to influence secondary factors such as cardiovascular, social or cognitive morbidities because the patient's functionality is already affected at the time of diagnosis. This may in part explain why the current treatment modalities of SDB have only limited economic value in the short term as the influence on direct and indirect costs is decreased when an accurate diagnosis of SDB is delayed, clearly highlighting the need for early detection and intervention. In this study we also emphasise the influence of the diagnosis on the economic consequences of SDB as CPAP treatment had a positive effect on mortality but on economy within the observation period (2 years before and after). In a former national Health Technological Assessment performed under the supervision of the National Health Board, ${ }^{16}$ a minimum follow-up time of 8 years was needed before a positive effect on direct costs could be expected, and even longer if indirect costs were included. The factors influencing these calculations are sensitive to the

Table 5 Effect of CPAP treatment on economic consequences for patients with a diagnosis of snoring and sleep apnoea

\begin{tabular}{|c|c|c|c|c|c|c|c|c|c|c|c|c|c|}
\hline & \multirow{2}{*}{$\begin{array}{l}\text { No observed } \\
\text { years }\end{array}$} & \multicolumn{2}{|c|}{$\begin{array}{l}\text { In-hospital } \\
\text { costs }\end{array}$} & \multicolumn{2}{|c|}{$\begin{array}{l}\text { Outpatient } \\
\text { costs }\end{array}$} & \multicolumn{2}{|c|}{$\begin{array}{l}\text { Drug } \\
\text { treatment }\end{array}$} & \multicolumn{2}{|c|}{$\begin{array}{l}\text { Primary health } \\
\text { and private } \\
\text { practice } \\
\text { specialists }\end{array}$} & \multicolumn{2}{|c|}{ Social security } & \multicolumn{2}{|c|}{$\begin{array}{l}\text { Labour market } \\
\text { income }\end{array}$} \\
\hline & & Before & After & Before & After & Before & After & Before & $\overline{\text { After }}$ & Before & $\overline{\text { After }}$ & Before & After \\
\hline \multicolumn{14}{|l|}{ Snorers } \\
\hline Controls & 257397 & 466 & $602^{*}$ & 142 & $194^{*}$ & 218 & $252^{*}$ & 183 & $199 *$ & 3864 & $4243^{*}$ & 29833 & $29675^{*}$ \\
\hline No treatment & 40615 & 746 & $856^{*}$ & 260 & $326^{*}$ & 347 & $393^{*}$ & 278 & $302^{*}$ & 3956 & $4388^{*}$ & 30162 & $29750^{*}$ \\
\hline CPAP treatment & 300 & 1257 & 933 & 350 & 378 & 583 & $682^{*}$ & 301 & 321 & 4461 & $5373^{*}$ & 28517 & 27111 \\
\hline \multicolumn{14}{|l|}{ Sleep apnoea } \\
\hline Controls & 409046 & 551 & $714^{*}$ & 149 & $210^{*}$ & 253 & $292^{*}$ & 188 & $207^{*}$ & 4422 & $4894^{*}$ & 27728 & $26971^{*}$ \\
\hline No treatment & 57015 & 1299 & $1533^{*}$ & 297 & $396^{*}$ & 525 & $601^{*}$ & 334 & $366^{*}$ & 5454 & $6018^{*}$ & 24998 & $23916^{*}$ \\
\hline $\begin{array}{l}\text { Patients who returned } \\
\text { for CPAP within } 2 \text { years }\end{array}$ & 814 & 845 & $1269 * *$ & 332 & $441^{* *}$ & 645 & $711^{* *}$ & 357 & 348 & 5536 & $6467^{*}$ & 25318 & $24141^{* *}$ \\
\hline
\end{tabular}

${ }^{*} \mathrm{p}<0.001,{ }^{* *} \mathrm{p}<0.05$ (paired $\mathrm{t}$ test)

Obesity hypoventilation syndrome is not included as the number of observations is too small for a valid statistical analysis.

All costs are presented in euros adjusted to 2006 price levels.

CPAP, continuous positive airway pressure. 
Table 6 Repeated measures analysis between effects for patient and treatment groups and cost categories shown in table 5

\begin{tabular}{|c|c|c|c|c|c|c|}
\hline & $\begin{array}{l}\text { In-hospital } \\
\text { costs } \\
\text { p Value } \\
\end{array}$ & $\begin{array}{l}\text { Outpatient } \\
\text { costs } \\
\text { p Value }\end{array}$ & $\begin{array}{l}\text { Drug } \\
\text { treatment } \\
\text { p Value }\end{array}$ & $\begin{array}{l}\text { Primary health and } \\
\text { private practice } \\
\text { specialists } \\
\text { p Value } \\
\end{array}$ & $\begin{array}{l}\text { Social } \\
\text { security } \\
\text { p Value }\end{array}$ & $\begin{array}{l}\text { Labour market } \\
\text { income } \\
\text { p Value }\end{array}$ \\
\hline Control vs no treatment & $<0.0001$ & $<0.0001$ & $<0.0001$ & $<0.0001$ & 0.0001 & 0.756 \\
\hline Control vs CPAP & $<0.0001$ & $<0.0001$ & $<0.0001$ & $<0.0001$ & 0.1648 & 0.3468 \\
\hline Control vs return CPAP & 0.4247 & 0.001 & $<0.0001$ & $<0.0001$ & 0.2619 & 0.5184 \\
\hline CPAP vs return CPAP & 0.0338 & 0.9119 & 0.0787 & 0.6161 & 0.9881 & 0.9217 \\
\hline \multicolumn{7}{|l|}{ Sleep apnoea } \\
\hline Control vs no treatment & $<0.0001$ & $<0.0001$ & $<0.0001$ & $<0.0001$ & $<0.0001$ & $<0.0001$ \\
\hline Control vs CPAP & $<0.0001$ & $<0.0001$ & $<0.0001$ & $<0.0001$ & $<0.0001$ & 0.0002 \\
\hline Control vs return CPAP & 0.1128 & $<0.0001$ & $<0.0001$ & $<0.0001$ & $<0.0001$ & 0.3736 \\
\hline No treatment vs CPAP & $<0.0001$ & $<0.0001$ & $<0.0001$ & $<0.0001$ & 0.0039 & 0.5408 \\
\hline
\end{tabular}

Significance levels refer to the relative changes 2 years before and after diagnosis for the tested groups and cost categories.

CPAP, continuous positive airway pressure.

influence of factors such as time of disease detection, number of patients identified, diagnostic sensitivity and specificity of the diagnostic method, cost of screening and treatment, and effectiveness of treatment. Thus, organisation of the management of $\mathrm{SDB}$ and involvement of the primary sector are of significant importance for the earlier detection of SDB.

The total costs of treatments (CPAP, surgery (UPPP, adenotonsillectomy and other modalities)) are included in the total cost of SDB. The effect of this treatment is complex as no significant effect on mortality was identified with any treatment in patients who snored. In patients with SA, CPAP reduced mortality. We also included a sub-analysis of UPPP and adenotonsillectomy which showed no effect on mortality but a negative consequence on health economy. We did not include these results in this paper due to the heterogeneity of the ages and mortality (the mortality in this subgroup was lower owing to lower age and comorbidities). In patients with $\mathrm{OHS}$ the mortality rate was higher in the treated group, which may be due to the fact that the patients had more complicated disease. Another possibility is that the diagnosis and treatment accelerates the exit from the labour market, and early exit from the labour market because of poor health may be related to a higher mortality. ${ }^{18}$

There are some further limitations in this study: (1) the accuracy of the diagnosis and management are sensitive to the diagnostic criteria used by the reporting doctors; (2) the local management of treatment, especially CPAP, may be underreported; and (3) detailed information regarding CPAP usage and effect on SDB are not included.

This study, which includes data from all patients diagnosed with snoring, SA and OHS during an 8-year period in Denmark, found that these disorders lead to significantly higher healthrelated and social transfer costs and lower levels of employment and income. The study also identified a significant health-related impact and socioeconomic aspect of these conditions, suggesting a need to further address the relevance of early diagnosis of $\mathrm{SDB}$ and measurement of the effect of treatment. Adequate treatment may reduce the consequences of SDB but, if socially and economically significant reductions in morbidity, mortality and social impact are to be achieved, much earlier disease identification and management are needed. There is therefore a need for evaluation of a general screening and disease management programme. Appropriate diagnostic facilities and treatment must be provided to increase quality of life and to decrease the risk of secondary complications (especially CVD) and the negative influence on employment. Research should also be undertaken to evaluate whether interventions lead to improvements in quality of life, socioeconomic factors, work capabilities and healthcare needs and reduce costs for patients and society.

Funding This study was supported by an unrestricted grant from the Respironics Foundation and from a grant from Center for Healthy Aging, Faculty of Health Sciences, University of Copenhagen.

\section{Competing interests None.}

Ethics approval The study was approved by the Danish Data Protection Agency. Because data handling was anonymous, individual and ethical approval was not mandatory.

Contributors PJ and JK created the ideas, JK did most of the statistical analysis, PJ wrote the paper.

Provenance and peer review Not commissioned; externally peer reviewed.

\section{REFERENCES}

1. Jennum P, Riha RL. Epidemiology of sleep apnoea/hypopnoea syndrome and sleepdisordered breathing. Eur Respir J 2009;33:907-14.

2. McNicholas WT, Bonsigore MR; Management Committee of EU COST ACTION B26. Sleep apnoea as an independent risk factor for cardiovascular disease: current evidence, basic mechanisms and research priorities. Eur Respir J 2007:29:156-78.

3. McNicholas WT. Cardiovascular outcomes of CPAP therapy in obstructive sleep apnea syndrome. Am J Physiol Regul Integr Comp Physiol 2007;293:R1666-70.

4. Gibson GJ. Obstructive sleep apnoea syndrome: underestimated and undertreated. Br Med Bull 2005; 72:49-65

5. Li X, Sundquist K, Sundquist J. Socioeconomic status and occupation as risk factors for obstructive sleep apnea in Sweden: a population-based study. Sleep Med 2008;9:129-36.

6. Tarasiuk A, Greenberg-Dotan S, Simon T, et al. Low socioeconomic status is a risk factor for cardiovascular disease among adult obstructive sleep apnea syndrome patients requiring treatment. Chest 2006;130:766-73.

7. Weatherly HL, Griffin SC, Mc DC, et al. An economic analysis of continuous positive airway pressure for the treatment of obstructive sleep apnea-hypopnea syndrome. Int J Technol Assess Health Care 2009;25:26-34.

8. McDaid C, Griffin S, Weatherly $\mathrm{H}$, et al. Continuous positive airway pressure devices for the treatment of obstructive sleep apnoea-hypopnoea syndrome: a systematic review and economic analysis. Health Technol Assess 2009;13:iii-iv, xi-xiv, 1-119, 143-274.

9. Tan MC, Ayas NT, Mulgrew A, et al. Cost-effectiveness of continuous positive airway pressure therapy in patients with obstructive sleep apnea-hypopnea in British Columbia. Can Respir J 2008;15:159-65.

10. Guest JF, Helter MT, Morga A, et al. Cost-effectiveness of using continuous positive airway pressure in the treatment of severe obstructive sleep apnoea/hypopnoea syndrome in the UK. Thorax 2008;63:860-5.

11. Al Ghanim N, Comondore VR, Fleetham J, et al. The economic impact of obstructive sleep apnea. Lung 2008;186:7-12. 
12. Hillman DR, Murphy AS, Pezzullo L. The economic cost of sleep disorders. Sleep 2006;29:299-305

13. Wittmann V, Rodenstein DO. Health care costs and the sleep apnea syndrome. Sleep Med Rev 2004;8:269-79.

14. Douglas NJ, George CF. Treating sleep apnoea is cost effective. Thorax 2002;57:93.

15. Brouwer WB, Koopmanschap MA. How to calculate indirect costs in economic evaluations. Pharmacoeconomics 1998;13:563-9.
16. Jennum P, Folkersen J Andreasen J. Diagnostik og behandling af obstruktiv søvnapnø - en medicinsk teknologivurdering. Medicinsk Teknologivurdering Puljeprojekter 2006;6:1-104.

17. Efron B, Tibshirani RJ. An Introduction to the Bootstrap. London: Chapman \& Hall, 1993. 2008.

18. Brockmann H, Muller R, Helmert U. Time to retire-time to die? A prospective cohort study of the effects of early retirement on long-term survival. Soc Sci Med 2009;69:160-4.

\section{Journal club}

\section{Human neutrophil chemotaxis regulation by $\alpha-1$ antitrypsin}

$\alpha-1$ Antitrypsin (AAT) has anti-inflammatory roles beyond regulation of proteases. Chronic lung disease in $\alpha-1$ antitrypsin deficiency (AATD) is characterised by neutrophilic inflammation. This series of experiments investigated the effects of AAT on neutrophil chemotaxis by comparing neutrophils from patients with AATD with controls, both in vitro and in vivo.

Chemotaxis to both IL-8 and soluble immune complexes was increased in neutrophils from AATD patients when compared with controls, but chemotaxis was inhibited by exogenous AAT, with a dose-response effect. Similarly, in vivo, the increased chemotaxis of neutrophils from patients with AATD was normalised when they were treated with AAT augmentation therapy.

To investigate the mechanism behind this, further experiments identified that glycosylated AAT binds directly to IL-8, preventing the latter binding to its specific CXCR1 receptor, with consequent reduction in calcium influx into the cell and protein phosphorylation, components of the cascade of intracellular events which precede chemotaxis. In a second line of experiments, AAT was found to co-localise on the neutrophil membrane with the FcrRIIIB receptor. Shedding of this receptor is required for neutrophil chemotaxis, and this process is activated by the metalloproteinase ADAM17. AAT inhibited the shedding of the FcrRIIIB receptor via inhibition of ADAM17.

This study demonstrates that AAT inhibits neutrophil chemotaxis by two mechanisms: binding of IL-8 and inhibition of shedding of the FcrRIIIB receptor via ADAM17, providing new insight into its anti-inflammatory roles. As these effects were also seen in vivo, they increase our understanding of the therapeutic role of AAT augmentation therapy.

Bergin DA, Reeves EP, Meleady P, et al. $\alpha-1$ Antitrypsin regulates human neutrophil chemotaxis induced by soluble immune complexes and IL-8. J Clin Invest 2010;120:4236-50.

\section{H White}

Correspondence to L H White, Respiratory Department, Great Western Hospital, Swindon, UK; laura.white@gwh.nhs.uk

Published Online First 24 March 2011

Thorax 2011;66:566. doi:10.1136/thoraxjnl-2011-200116 